\title{
LIBERALISMO IGUALITÁRIO E AÇÃO AFIRMATIVA: DA TEORIA MORAL À POLÍTICA PÚBLICA
}

\author{
João Feres Júnior
}

\author{
Luiz Augusto Campos
}

\begin{abstract}
RESUMO
O presente artigo examina a hipótese de que a teoria política e moral do liberalismo igualitário serve de justificação para políticas de ação afirmativa de recorte étnico-racial, hipótese essa que tem sido assumida como verdadeira por acadêmicos e importantes operadores do direito em nosso país. Buscamos estabelecer como autores fundamentais do liberalismo igualitário, como John Rawls, Ronald Dworkin, Thomas Nagel e Robert Taylor, trataram a questão das políticas de discriminação positiva. O método usado é a interpretação textual, tomando cuidado de trabalhar o mais próximo possível da linguagem e dos conceitos nos próprios textos dos autores e cobrindo a evolução do tema na obra de cada um, particularmente na de Rawls. Pretendemos mostrar que há uma gradação de opiniões em relação à questão, que vai da defesa à rejeição de tais políticas, passando por posições intermediárias que justificam algumas modalidades de ação afirmativa, mas não outras. Portanto, não há uma relação unívoca entre a teoria política e moral do liberalismo igualitário e a justificação de políticas de ação afirmativa de recorte étnico-racial, a despeito do senso comum e do fato de teóricos do liberalismo igualitário e defensores da ação afirmativa partilharem o mesmo lugar no espectro político das democracias liberais.
\end{abstract}

PALAVRAS-CHAVE: teoria política; ação afirmativa; liberalismo igualitário; justiça; Rawls.

\section{INTRODUÇÃO ${ }^{1}$}

A teoria da justiça do liberalismo igualitário, cujo maior expoente é John Rawls, tem sido frequentemente usada como fonte de justificação das políticas de ação afirmativa. "Só para citar um exemplo recente e de muita importância, o Ministro do Supremo Tribunal Federal, Ricardo Lewandowski cita o próprio Rawls no seu voto como relator da Arguição de Descumprimento de Preceito Fundamental n. 186 - ajuizada pelo partido Democratas contra a política de cotas étnico-raciais da Universidade de Brasília (UnB) - para defender "a intervenção estatal determinada e consciente" para corrigir as desigualdades reais da sociedade, "realocando-se os bens e oportunidades existentes na sociedade em benefício da coletividade como um todo". (LEWANDOWSKI, 2012, p. 7).

Lewandowski, em seguida, cita literalmente os dois princípios da justiça postulados por Rawls em Uma Teoria da Justiça (RAWLS, 1971). É interessante notar que o Ministro em vez de optar pela formulação final dos princípios de Rawls, aquela que contém o Princípio da Diferença - "as desigualdades econômicas e sociais devem ser ordenadas de modo a serem ao mesmo tempo

\footnotetext{
1 Agradecemos aos pareceristas anônimos da Revista de Sociologia e Politica pelas sugestões a este artigo.
}

para o maior beneficio esperado dos menos favorecidos" - escolhe uma formulação provisória na qual "as desigualdades econômicas e sociais devem ser ordenadas de modo que sejam [...] consideradas como vantajosas para todos dentro dos limites do razoável" (Rawls apud LEWANDOWSKI, 2012, p. 7).

Qual a razão que levou o Ministro a agir dessa maneira? A formulação do Princípio da Diferença parece ser, à primeira vista, mais apropriada à defesa da justiça - e, assim, da legalidade e da constitucionalidade da ação afirmativa étnico-racial, coisa que seu relatório faz decididamente. Contudo, uma vez que um dos argumentos mais comuns dos opositores das cotas é o de que a desigualdade no Brasil é de natureza puramente econômica e não racial (KAMEL, 2003), talvez o Ministro não tenha querido dar um caráter marcadamente econômico à sua defesa, caráter esse que o Princípio da Diferença apresenta claramente. Ou seja, ao fazer tal opção, o Ministro estaria argumentando que a ação afirmativa se justificaria mesmo para negros que não estejam entre os "menos favorecidos".

É difícil estabelecer com certeza a razão de tal escolha. Fato é que os votos de juízes, a despeito de sua possível carga teórica, como é o caso em pauta, não seguem a lógica da argumentação científica, ou acadêmica, mas sim uma lógica argumentativa que contém elementos de retórica e de simbolismo cultural 
e político. Neste ensaio, propomos encarar com seriedade a questão da interlocução entre liberalismo igualitário e ação afirmativa étnico-racial, postulando a seguinte questão: será que o liberalismo igualitário provê uma justificação inequívoca para as políticas de ação afirmativa de cunho étnico-racial? Por meio da análise das contribuições de autores fundamentais dessa corrente teórica, pretendemos mostrar que há uma gradação de opiniões em relação à questão que vai da defesa explícita à rejeição de tais políticas, passando por posições intermediárias que incluem sua não tematização. $\mathrm{Na}$ conclusão sintetizaremos esses resultados para melhor avaliarmos a percepção de que a resposta à questão seria positiva.

A título de ressalva, é importante salientar que outras vertentes da teoria política e moral podem ser, e de fato são, usadas na justificação das políticas de ação afirmativa, como o comunitarismo (p. ex., SANDEL, 1982; WALZER, 1983), o multiculturalismo (YOUNG, 1990; KYMLICKA, 1995), ou mesmo a teoria do reconhecimento (TAYLOR, 1992), ainda que tal conexão seja muitas vezes interpretada erroneamente por comentadores dentro e fora da academia. Trataremos desse assunto em outra oportunidade. Por ora, focamos o liberalismo igualitário, que é em si uma vertente teórica importante e muito influente, não somente no debate público de países democráticos contemporâneos, mas também na teoria política e no Direito, particularmente quando o assunto em pauta são políticas públicas, como é o caso em questão.

\section{RAWLS EAAÇÃO AFIRMATIVA}

O ponto de onde devemos começar é o trabalho de John Rawls, pois ele é a referência maior e primeira do liberalismo igualitário. Seu livro $A$ Theory of Justice (RAWLS, 1971) inaugurou um debate sobre justiça no âmbito da teoria política que até hoje não se extinguiu, e que se espalhou por outras disciplinas, inclusive para o estudo das políticas públicas e do Direito, como podemos constatar com a citação do ministro.

A questão, portanto, que devemos colocar é se a teoria de Rawls, considerando não somente $A$ Theory of Justice, mas os textos que publicou posteriormente, justifica a adoção de políticas de ação afirmativa, mais especificamente, de políticas de ação afirmativa de recorte racial. A resposta a essa questão não é simples, a despeito da associação recorrente entre uma coisa e outra feita por acadêmicos, juristas e publicistas. Para examinarmos corretamente o assunto, vamos desmembrar a questão em duas partes, primeiro respondendo-a no que concerne a ação afirmativa em geral e depois à sua variante étnico-racial. Para tal, é necessário que, ainda que brevemente, definamos o que são políticas de ação afirmativa.

A despeito de alguma variação na maneira como são definidas (GOMES, 2001; FERES JÚNIOR, 2004; WEISSKOPF, 2004), a literatura especializada parece concordar que ações afirmativas são políticas, públicas ou corporativas privadas, que visam promover uma determinada categoria social sub-representada em algum espaço institucional ou função. Como tal, é política redistributiva, pois altera uma dada distribuição de bens e oportunidades, imprimindo-lhe outra configuração. Ajustificativa para tal alteração é sempre um argumento de justiça, ou seja, produzir uma configuração social mais justa, muitas vezes atrelado a argumentos de expediência, como a promoção de maior bem-estar total, maior coesão social, sentido mais forte de cidadania etc. (ver, por exemplo, ZONINSEIN, 2004) $)^{2}$.

Os argumentos de justiça mais empregados na justificação pública das políticas de ação afirmativa são reparação, "justiça social" e diversidade (FERES JÚNIOR, 2004). Na verdade, somente os dois primeiros podem ser considerados argumentos de justiça puros, pois justificam a adoção de uma medida a despeito do seu resultado. Isto é, uma vez aceitos tais argumentos, justificam que políticas sejam criadas mesmo que a expectativa do resultado dessas políticas não seja um aumento da utilidade geral. No caso da reparação, como o próprio nome sugere, as iniciativas visam restituir ou mitigar perdas provenientes de injúria ou crime do passado - a escravidão é o exemplo mais claro e também mais significativo para o tópico em questão. O termo "justiça social", usado aqui entre aspas para denotar um uso específico de uma expressão que na linguagem corrente tem um significado mais amplo: aplica-se ao argumento de que qualquer desigualdade injustificada constitui de fato uma injustiça que potencialmente deve ser de alguma maneira mitigada por ação estatal. Por exemplo, o fato de que homens que ocupam a mesma função no trabalho que mulheres terem em média salário maior é, nos padrões morais e legais de hoje, injustificável.

$\mathrm{O}$ argumento da diversidade, da maneira como é empregado nos Estados Unidos, é em grande medida baseado na expediência, ou seja, no suposto ganho

2 É preciso aqui anotar a diferença entre teorias de justiça categóricas, como, por exemplo, a de Kant, quando a justiça é servida a despeito da utilidade das consequências, e teorias consequencialistas, como o utilitarismo de Jeremy Bentham, entre outros, onde a justiça é uma função da utilidade das consequências. 
de qualidade de ensino e de serviço que um corpo estudantil formado por pessoas de diversas origens sociais e culturais proporcionaria. Além de integrar o vocabulário do inglês cotidiano, o conceito de diversidade foi central em decisões da Suprema Corte daquele país em casos-chave que versaram sobre políticas de ação afirmativa, como Regents of the University of California (como Bakke, de 1978, e Grutter v. Bollinger, de 2003), cujo objeto eram as políticas de ação afirmativa para negros na Universidade de Michigan. A decisão da Corte no caso Bakke, escrita pelo Ministro Powell, ressalta que a diversidade é a única razão para se considerar legal o uso do critério "raça", entre outros, na seleção de candidatos para cursos universitários. E isso porque ela contribui para a melhoria da qualidade de ensino, ao submeter o ambiente acadêmico a um conjunto mais rico de experiências de vida, formando assim profissionais mais competentes, conhecedores de um conjunto maior de realidades sociais (BALL, 2000).

Tal opinião tornou-se o padrão interpretativo na Corte em casos posteriores que versavam sobre o mesmo assunto, como Grutter v. Bollinger. O que é importante ressaltar aqui é que a justificativa não é a justiça em si ou a luta contra a desigualdade, mas sim o aumento da qualidade do serviço educacional prestado pelas universidades. O julgamento do caso Grutter v. Bollinger anotou um recorde de participação de amici curiae, decididamente em favor da constitucionalidade da ação afirmativa de recorte étnico-racial. Essa posição foi partilhada por 65 empresas de grande porte, entre elas General Electric, Microsoft, IBM, General Motors e Coca-Cola, e também por um grupo de altos oficiais do exército que incluía o General H. Norman Schwarzkopf, comandante do exército norte-americano na Guerra do Golfo (1991). Os amici curiae esforçaram-se em mostrar que a grande virtude da diversidade promovida pela ação afirmativa residia na melhoria do serviço prestado por um corpo de funcionários diverso, capaz de atender uma população também diversa.

$\mathrm{O}$ argumento da reparação não se combina bem com a teoria deontológica de Rawls que é, como aponta corretamente seu crítico libertário, Robert Nozick, insensível à trajetória histórica que produziu um determinado padrão presente de desigualdades (NOZICK, 1974, p. 153). De fato, a injustiça e a justiça na teoria de Rawls podem ser determinadas a partir de uma dada distribuição presente, sem que precisemos recorrer a informações sobre as causas históricas que produziram tal distribuição. Assim, se há alguma ligação entre a teoria desse autor e a justificação da ação afirmativa, essa ligação não é por meio do argumento da reparação.

Quanto ao argumento da diversidade, como sugerimos acima, não se trata propriamente de um argumento de justiça, ainda que o discurso da diversidade na linguagem comum esteja misturado a um senso difuso de justiça, expressão da percepção de que a diversidade de uma sociedade deve estar espelhada em suas subunidades, particularmente em espaços de poder e prestígio. Pelo menos no âmbito dos argumentos teóricos e legais, o elemento mais saliente de tal argumento é o da expediência, isto é, da utilidade, talvez por influência do juiz Powell, cuja opinião tornou-se o padrão de interpretação da constitucionalidade da ação afirmativa nos Estados Unidos. Logo, o argumento da diversidade da maneira como é utilizado não pode ser diretamente derivado da teoria da justiça como equidade rawlsiana, ainda que, como mostraremos mais adiante, a reformulação proposta por Rawls em Political Liberalism (RAWLS, 1993) tenta dar conta desse aspecto social, ainda que por outras vias que não propriamente a aplicação direta do critério da diversidade a mecanismos redistributivos.

Desde já, podemos notar a compatibilidade entre o argumento da "justiça social" enunciado aqui "qualquer desigualdade injustificada constitui de fato uma injustiça que potencialmente deve ser de alguma maneira mitigada por ação estatal" - e a teoria de Rawls. Assim, passamos a examinar essa compatibilidade, tratando primeiro da ação afirmativa em geral, da maneira genérica como definimos acima, para depois analisar a política com foco étnico-racial.

Para que tal compatibilidade torne-se clara é preciso reconstruir o argumento de Rawls em $A$ Theory of Justice. Da maneira em que é primeiramente enunciado, como definição provisória, o segundo princípio da justiça reza que as desigualdades econômicas e sociais devem ser arranjadas de maneira a serem (i) para a vantagem de todos e (ii) relacionados a posições e cargos abertos a todos (RAWLS, 1971, p. 60). O autor, em seguida, acrescenta que os dois princípios da justiça, como estão na definição provisória, podem ser interpretados pelo menos de quatro maneiras diferentes, que dariam origem a quatro modelos jurídicos: sistema de liberdade natural, igualdade liberal, aristocracia natural e igualdade democrática (idem, p. 65). Contudo, somente a interpretação da igualdade democrática, que conjuga o princípio da diferença com a igualdade justa de oportunidades, está de acordo com a teoria da justiça como equidade proposta pelo autor. As outras 
interpretações falham por não prover mecanismos suficientes para mitigar os efeitos dos dois fatores moralmente arbitrários que são geradores de desigualdades: posição social de nascimento e talentos e habilidades naturais (idem, p. 74-75). Assim, Rawls reformula o segundo princípio da justiça da seguinte maneira: desigualdades sociais e econômicas devem ser arranjadas de modo que sejam (i) para o maior benefício dos menos privilegiados e (ii) relacionados a posições e cargos abertos a todos sob condições de igualdade de oportunidades. Em outras palavras, (i) é o princípio da diferença e (ii) a igualdade de oportunidades (Rawls, 1971, p. 83).

Nesse ponto devemos chamar atenção para uma questão terminológica importante. A expressão "igualdade de oportunidades" em inglês é usada muitas vezes como sinônimo puro e simples de ação afirmativa. Só para citar um exemplo significativo, a principal agência de promoção de políticas de ação afirmativa étnico-raciais do governo norte-americano chama-se Equal Employment Opportunity Commission (EEOC) e foi criada em julho de 1965, em cumprimento do Título VII do Civil Rights Act de 1964. Uma miríade de políticas de ação afirmativa norte-americanas criadas desde a década de 1960 atende pelo nome de programas de "igualdade de oportunidades". Isto é, Rawls não somente adota tal expressão, já carregada de significados associados à ação afirmativa na época da redação do livro, como não faz qualquer ressalva contra tal associação, coisa que necessariamente deveria ser feita caso o autor assim intencionasse. Tal ressalva tampouco aparece na versão revisada do livro que o autor publicou 20 anos depois (RAWLS, 1999).

Rawls explicitamente cita a educação de qualidade aberta a todos como um dos elementos da promoção da igualdade de oportunidades na passagem em que discute a interpretação liberal dos dois princípios (RAWLS, 1971, p. 73), dando a entender que tal política seria necessária, mas não suficiente para um sistema com real igualdade de oportunidades. Tal sistema somente seria atingido com o pleno funcionamento de políticas de igualdade de oportunidade com o princípio da diferença. Isto é, o autor parece sugerir que a igualdade de oportunidades opere como princípio não somente no âmbito da educação. É preciso também notar que o sentido mais geral da contribuição de Rawls, expresso no motivo justice as fairness, é o de que a justiça não pode ser reduzida ao formalismo da norma universal, como querem libertários e neoliberais - como, por exemplo, Hayek (1960) - mas que ela tem de ser baseada em um sentimento de justiça (fairness), que é um aspecto fundamental do sujeito moral e do sistema de cooperação social como um todo ${ }^{3}$. Assim, as instituições básicas da sociedade devem sim promover redistribuição de bens e oportunidades.

Tal redistribuição, típica do Estado de Bem-Estar social $^{4}$, corresponde na prática a violações tópicas do princípio da igualdade legal. Ora, o patrimônio do Estado é propriedade de todos os cidadãos, tomados como seres iguais que, por isso partilham dele, cada um, na mesma proporção. Qualquer política que redistribua tais fundos assimetricamente, privilegiando, por exemplo, crianças pobres, desempregados, moradores do Vale do Mississipi ou do Sertão Nordestino, está de fato violando topicamente o princípio da igualdade de todos, pois, se tal princípio fosse sustentado sem reservas ou ressalvas, nenhuma

\footnotetext{
3 Aqui nos deparamos com uma situação em que o entendimento da mensagem precisa estar atento às sutilezas linguísticas. A melhor tradução da palavra fairness para o português é "justiça". Mas a melhor tradução da expressão justice as fairness não pode ser "justiça como justiça", por razões óbvias. A escolha da expressão "justiça como equidade", feita pelo tradutor de Rawls, não resolve satisfatoriamente a questão, pois o termo equidade introduz problemas de outra ordem, que tem a ver com a definição analiticamente imprecisa dessa palavra e sua diferenciação com o termo "igualdade". A sugestão de que equidade corresponderia à aplicação do princípio da justiça distributiva de Aristóteles - tratar os iguais como iguais e os desiguais como desiguais à medida de sua desigualdade - é analiticamente pobre por duas razões. Primeiro, porque para Aristóteles tal princípio comanda dar mais a quem mais contribui e menos a quem menos contribui ao bem público, ou seja, ele é regressivo, ao contrário do que imaginam muitas das pessoas que citam o filósofo como fonte. Segundo, porque a interpretação de que os que têm menos devem receber mais, sugerida pela ideia de equidade, parece advir mais de um sentimento de caridade pelos despossuídos do que de um esquema contratualista, como o proposto por Rawls, onde as pessoas adotam tal princípio guiados pela razão e com vistas ao benefício próprio. De qualquer forma, a despeito da dura tarefa de encontrar-se uma tradução melhor para a expressão, devemos sublinhar o sentido que o autor quis dar de uma justiça que vá além do puramente formal, mitigando, ainda que por mecanismos procedimentais, os fatores reais de desigualdade injustificável que assolam a sociedade.
}

4 Depois da primeira versão de A Theory of Justice, Rawls tentou várias vezes mostrar as incongruências de sua teoria com o modelo redistributivo do Estado de Bem-Estar. Segundo ele, tal modelo estaria muito mais preocupado em manter condições mínimas de dignidade para seus cidadãos do que em controlar as desigualdades (Rawls, 1999, p. XV). Ademais, esse modelo não tomaria a propriedade privada como objeto dos princípios de justiça, posição contrária a de Rawls (idem, p. XIV). A despeito dessas diferenças, o Estado de Bem-Estar é certamente o modelo político, historicamente realizado, que melhor se conforma à teoria justiça como equidade, ainda que tal conformação seja parcial. 
política dessa natureza seria possível. Como justificar, então, essa violação tópica do princípio da igualdade perante a lei? De duas formas possíveis: ou como reparação à opressão e discriminação historicamente sofridas por tal ou qual categoria social ou como justiça social, devido ao fato de as desigualdades às quais tal categoria social está sujeita não serem justificáveis. Dessa maneira, podemos facilmente notar que a ação afirmativa, tal como a definimos genericamente, constitui exatamente uma política dessa espécie, ou seja, uma política típica do Estado de Bem-Estar social. E também plenamente justificada pela teoria da justiça de Rawls, pois esse se encaixa perfeitamente em nossa concepção de justiça social - uma vez, é claro, que o primeiro princípio da justiça, aquele que comanda a distribuição igual de direitos básicos, seja respeitado. É preciso ter claro que o segundo princípio trata do tema da justificação de desigualdades sociais. Ele é um critério a partir do qual podemos dizer que algumas desigualdades são justificáveis e outras não.

Resta saber, contudo, se no âmbito da teoria de Rawls qualquer categoria social pode ser legitimamente acionada pelo princípio da diferença e contemplada com o esquema de igualdade de oportunidades. Rawls, de fato, refere-se explicitamente ao menos privilegiados (least advantaged). Então, para sermos mais precisos, a pergunta deve ser reformulada: serviriam categorias étnico-raciais como espécies nesse gênero? A resposta não é simples, e isso se deve em grande parte à argumentação pouco clara apresentada pelo autor quando se depara, ainda que lateralmente, com a questão.

Segundo Rawls, em seu exercício deontológico, os princípios da justiça devem ser aplicados à estrutura básica da sociedade levando em conta certos "indivíduos representativos" (idem, p. 95). Tais indivíduos representariam posições sociais relevantes. Escreve o autor que todo indivíduo tem duas posições relevantes, uma no âmbito dos deveres e direitos e outra definida pela sua posição na distribuição social de renda e riqueza (idem, p. 96) ${ }^{5}$. No que toca o primeiro âmbito, os indivíduos devem ser todos iguais, ter a mesma parcela. Assim, é somente a posição social o dado que determina a posição relevante dos indivíduos representativos. Mesmo o poder e a autoridade, acrescenta Rawls, podem ser subsumidos

5 Que se sobrepõem perfeitamente aos dois princípios da justiça como equidade.

6 O fato de o autor considerar a cultura uma característica natural contribui para a falta de clareza do tratamento do tópico em seu texto. Rawls não explica como cultura pode ser tratada como tal. Não obstante, a concepção norte-americana de sob o critério da riqueza e renda, pois essas são coisas altamente correlacionadas. Ao colocar-se o problema prático de definir essas posições, Rawls elege o critério de renda ou de ocupação, ou mesmo uma combinação entre os dois, como soluções suficientes (idem, p. 96). Em suma, o critério defendido pelo autor é econômico. Mas Rawls não deixa a questão nesse ponto sem antes contemplar o problema das desigualdades baseadas em "características naturais fixas", entre as quais ele identifica o gênero, a raça e a cultura $(\mathrm{sic})^{6}$. A passagem vale a pena ser citada: "Algumas vezes, contudo, outras posições podem ser levadas em conta. Se, por exemplo, há direitos básicos desiguais fundados sobre características naturais fixas, essas desigualdades definirão posições relevantes. Uma vez que tais características não podem ser mudadas, as posições que elas definem contam como ponto de partida na estrutura básica. Distinções baseadas em sexo são desse tipo, assim como aquelas relacionadas à raça e cultura" (idem, p. 96) ${ }^{7}$.

Declara Rawls que o fato dos homens serem favorecidos pelo esquema de distribuição de direitos básicos ${ }^{8}$ só poderia ser justificado se esse favorecimento fosse vantajoso para as mulheres e justificado de seu ponto de vista. É claro que não é, conclui o autor, assim como não poderia ser para o caso análogo da desigualdade racial ou étnica, acrescenta ele. Assim, tais desigualdades multiplicariam as posições relevantes. Isso é, até esse ponto, Rawls parece sim concordar com o argumento de que a desigualdade racial seria razão suficiente para pensar-se em um indivíduo representativo "racializado" na posição de discriminado quando do cálculo da aplicação dos dois princípios. Mas a conclusão que se segue vai em outro sentido: "Por outro lado, essas

etnicidade, que é de fato uma categoria onde percepções raciais misturam-se com percepções culturais (SANSONE, 2003), pode estar no fundo de tal opção, ainda que não sirvam como desculpa para a falta de clareza acerca de um conceito tão importante para o debate contemporâneo.

7 Tradução nossa da passagem: "Sometimes, however, other positions may need to be taken into account. If, for example, there are unequal basic rights founded on fixed natural characteristics, these inequalities will single out relevant positions. Since these characteristics cannot be changed, the positions they define count as starting places in the basic structure. Distinctions based on sex are of this type, and so are those depending upon race and culture" (RAWLS, 1971, p. 96).

8 Rawls define direitos básicos como as condições sociais e políticas essenciais para o desenvolvimento e exercício pleno dos poderes morais de pessoas livres e iguais, que no fundo são basicamente direitos civis e políticos (RAWLS \& KELLY, 2001, p. 45). 
desigualdades são raramente vantajosas para os menos favorecidos, e, assim, em uma sociedade justa um número menor de posições relevantes deve ser suficiente" (idem, p. 99) 9 .

A despeito da redação pouco clara, Rawls está sugerindo aqui que as desigualdades raciais não são relevantes o suficiente para que não possam ser consideradas como subsumidas pelas desigualdades sociais. Um argumento que vemos repetido frequentemente no debate sobre ação afirmativa em nosso país: cotas sociais resolveriam o problema, sem a necessidade de adotarmos políticas de viés étnicoracial. Ele acrescenta que, do ponto de vista de posições específicas, os dois princípios nem sempre funcionam de maneira benéfica, por isso é importante pensar o esquema proposto em termos somente das posições relevantes. O exemplo dado agora é o de uma indústria cujos interesses residem na proteção de mercado e que não pode sobreviver em um ambiente de livre mercado. Rawls argumenta que se o livre mercado for benéfico do ponto de vista da igualdade dos direitos (primeiro princípio) e também para os menos privilegiados, então ele deve imperar, mesmo que aquele ramo particular de atividade sofra.

A solução é de fato analiticamente confusa, pois Rawls chama primeiramente as situações de gênero, raça ou etnia de "naturalmente fixadas", para concluir que elas determinam posições relevantes. Mas, ao subsumi-las sob o critério econômico, lança mão do exemplo dos interesses de um ramo industrial protecionista. Os dois exemplos não são equivalentes do ponto de vista moral adotado pelo próprio autor, pois enquanto as características "naturalmente fixadas" são "moralmente arbitrárias", ou seja, são adscritas a despeito da escolha do sujeito, os interesses industriais advêm da opção que um grupo de pessoas faz de perseguir esse ou aquele ramo de atividade, opção essa, inclusive, que pode ser alterada no transcurso de suas vidas. Em outras palavras, desigualdades provenientes de situações de gênero, raça ou etnia - particularmente se consideradas "naturalmente fixadas", como faz o autor - deveriam ser importantes para uma teoria que se propõe a mitigar os efeitos perversos do acidente da posição social do nascimento e da loteria das capacidades, pois são igualmente arbitrárias do ponto de vista moral. Rawls tenta livrar-se do problema com um coup de main, que não funciona a contento.

9 Tradução nossa da passagem: "On the other hand, these inequalities are seldom, if ever, to the advantage of the less favored, and therefore in a just society the smaller number of relevant positions should ordinarily suffice" (RAWLS, 1971, p. 99).
Na revisão que fez de seu livro, publicada em 1999, Rawls não mudou uma linha das poucas passagens que toca no assunto (RAWLS, 1999). Já em Political Liberalism, o tema aparece novamente de maneira lateral e recebe tratamento similar. Rawls diz que na sociedade contemporânea os problemas relacionados à "raça, etnicidade e gênero" parecem ser os mais importantes, e que, portanto, eles apontariam para a elaboração de princípios da justiça "diferentes", coisa que não foi feita em $A$ Theory of Justice. Contudo, Rawls assevera que seu objetivo no livro anterior foi tratar questões clássicas levantadas pela teoria liberal, que dão conta do funcionamento nas instituições básicas da sociedade, deixando vários detalhes e situações particulares de aplicação da justiça sem serem discutidas (RAWLS, 1993, p. xxvii-xxviii). E isso é tudo.

O autor só elabora mais a questão em Justice as Fairness (RAWLS \& KELLY, 2001). Em uma longa nota para explicar o significado da categoria "menos privilegiados" ele afirma que esses não são nunca identificados sem referência a sua renda e riqueza. E acrescenta: "Os menos favorecidos não são identificáveis como homens ou mulheres, brancos ou negros, indianos ou britânicos. Eles não são indivíduos identificados por características naturais ou de outra ordem (raça, gênero, nacionalidade etc.) de maneira a nos permitir comparar sua situação sob vários esquemas de cooperação social concebíveis" (idem, p. 59) ${ }^{10}$.

O ponto aqui é que, a despeito do esquema social de cooperação, os "menos privilegiados" sempre estarão por baixo, enquanto que categorias marcadas por lugares fixos podem variar sua posição de um esquema a outro. Certamente, a nota esclarece a passagem de $A$ Theory of Justice, citada acima, pelo menos no que toca a expressão clara das ideias do autor. Resta ainda a dúvida acerca da natureza das categorias escolhidas, pois a maneira como são descritas pelo autor sofre de duas deficiências argumentativas: $(i)$ primeiro, a condição de "menos privilegiado" pode ter um componente natural, que são as habilidades inatas e (ii) as Ciências Sociais já mostraram repetidas vezes que categorias como raça e gênero não são naturais, mas socialmente construídas. O que une todas essas categorias discricionárias (talentos naturais, posição de

\footnotetext{
10 Nossa tradução do trecho: "The least advantaged are never identifiable as men or women, say, or as whites or blacks, or Indians or British. They are not individuals identified by natural or other features (race, gender, nationality, and the like) that enable us to compare their situation under all the various schemes of social cooperation it is feasible to consider" (RAWLS \& KELLY, 2001, p. 59).
} 
nascimento, gênero, raça e etnia até certo ponto) é o fato de não serem produto da escolha das pessoas e, portanto, serem moralmente arbitrárias, e não de serem "naturais" ou socialmente construídas. Mas Rawls, em sua procura incessante por estabelecer critérios universais, nega-se a admitir critérios não econômicos na operação de seus princípios da justiça ${ }^{11}$.

O assunto não se esgota aí, contudo. Ele retorna quando Rawls discute as três contingências moralmente arbitrárias. Diferentemente de $A$ Theory of Justice, nesse novo trabalho o autor incorpora a sorte ou azar que temos no curso de nossas vidas como terceiro fator fortuito, além da posição social de nascimento e dos talentos inatos (RAWLS \& KELLY, 2001, p. 55). O autor então se pergunta por que gênero e raça não são enumerados entre essas contingências. A resposta é que, no plano da teoria ideal, devem ser consideradas somente as contingências que geram desigualdades mesmo na sociedade bem ordenada. Ademais, os menos privilegiados são definidos não por características naturais, mas por um índice de acesso aos bens primários. Finalmente o argumento começa a ficar mais claro: a adoção do critério econômico é defendida porque ele funcionaria a despeito de como o arranjo social lida com a valorização ou não de critérios "naturais" como raça, gênero, talentos naturais etc. ${ }^{12}$ Assim, o autor parece sugerir que o critério econômico deve dar conta da promoção da justiça como equidade. Tal argumento é de fato comum no debate sobre inclusão e democratização no acesso à universidade no Brasil, figurando entre os principais no campo daqueles que rejeitam a adoção de políticas de ação afirmativa de corte étnico-racial. Em sua expressão mais corriqueira ele é assim apresentado: cotas sociais resolveriam o problema da desigualdade de acesso entre brancos e não brancos.

11 Como assevera Will Kymlicka, corretamente, até a década de 1980 o mainstream da teoria política foi ativamente contrário a incluir esses problemas na sua pauta os temas do gênero, raça e etnia (KYMLICKA, 2001). Rawls é um exemplo muito significativo, seja por sua proeminência no debate, seja pela tentativa de dar conta da questão da diferença "cultural" legitimação de instituições em um contexto de pluralismo razoável - a partir de Political Liberalism, ainda na chave do pluralismo "tradicional" (DAHL \& FLANIGAN, 1971), que reduz tal questão a uma representação da diferença religiosa entre cristãos, quando não entre diferentes denominações protestantes, como Rawls mesmo nos deixa antever na longa introdução de Political Liberalism (RAWLS, 1993).

12 Rawls assim se livra da crítica, feita entre outros por Nozick (1974), que sua teoria na verdade operaria uma redistribuição baseada em características naturais, como a falta relativa de habilidades naturais.
Mas dessa vez, a questão não é abandonada com facilidade, pois algumas páginas adiante, Rawls volta a perguntar-se por que as distinções de raça e de gênero não foram adicionadas às três contingências. A passagem faz referência a fatos históricos e tem um tom dramático não muito comum aos textos do autor: "Como podemos ignorar fatos históricos como a escravidão (no Sul préGuerra Civil) e as desigualdades entre homens e mulheres que resultam da falta de provisões para compensar a carga extra que mulheres têm por carregar, criar e educar as crianças, de maneira a garantir a elas igualdade justa de oportunidades?" (idem, p. 65) ${ }^{13}$.

Ele primeiro repete a resposta de que na teoria ideal somente as contingências que produzem desigualdades "inquietantes" na sociedade bem-ordenada devem ser levadas em conta, e que a riqueza seria critério suficiente para identificar os menos privilegiados (ibidem). Mas logo em seguida o autor emenda: "entretanto, algumas vezes outras posições devem ser levadas em conta" (ibidem). Isso acontece quando características naturais são usadas para adscrever direitos e oportunidades desiguais. Nesse caso, essas desigualdades caracterizam posições relevantes que, dado o fato de que tais características não podem ser mudadas, constituem pontos de vista que devem ser levados em consideração na organização da estrutura básica da sociedade justa, isto é, no esquema de redistribuição de bens primários (primary goods) ${ }^{14}$.

Para o autor, distinções de gênero e raça encaixamse nessa categoria. Nessa passagem de Justice as Fairness ele repete quase ipisis literis o texto de $A$ Theory of Justice, já comentado por nós acima, no qual argumenta que tais desigualdades só poderiam ser justificadas se fossem vantajosas para quem as sofre. Mas é claro que elas de fato não são, e parece que "nunca foram". Nesse ponto, Rawls, que parecia estar conduzindo o argumento para a aceitação do uso

13 Tradução nossa do trecho: "How can one ignore such historical facts as slavery (in the antebellum South) and the inequalities between men and women resulting from the absence of provisions to make good women's extra burden in the bearing, raising, and educating children so as to secure their fair equality of opportunity?" (RAWLS \& KELLY, 2001, p. 65).

14 É importante deixar claro que a lista de bens primários definida por Rawls é extensa, e inclui uma gama de direitos civis, políticos e sociais e também oportunidades. Ele classificaos em cinco grupos: (i) direitos e liberdades básicas; (ii) liberdade de movimento e de escolha livre da ocupação; (iii) poderes e prerrogativas de postos e posições de autoridade e responsabilidade; (iv) renda e riqueza e $(v)$ bases sociais do autorrespeito, que são os aspectos institucionais que permitem aos cidadãos adquirir "um senso de valor como pessoas e serem capazes de perseguir seus objetivos com autoconfiança" (idem, p. 58-59). 
de tais categorias na formulação das medidas redistributivas, novamente recua dizendo que como não podemos ter certeza absoluta que historicamente esse vai ser sempre o caso (de que as desigualdades são desvantajosas para mulheres e minorias raciais), na sociedade bem-ordenada as posições relevantes que dizem respeito à divisão dos bens primários devem ser suficientes (idem, p. 66). Isto é, se antes o critério para a determinação das posições relevantes parecia ser somente a renda, agora é um rol bem mais amplo de bens primários.

Para tentar dar fecho a seus argumentos, Rawls escreve dois parágrafos introduzidos pela cláusula: "para concluir". E essa conclusão é ao mesmo tempo reveladora e frustrante. Reveladora, pois deixa claro o processo de vai e vem dos argumentos do autor, agora sintetizado em poucas linhas, e frustrante porque a conclusão é menos que satisfatória para a determinação de uma posição clara. "Quando usadas de um determinado modo, distinções de gênero e raça dão origem às posições relevantes às quais uma forma especial de princípio da diferença se aplica. Esperamos que em um sociedade bem-ordenada sob condições favoráveis, com iguais liberdades básicas e igualdade justa de oportunidades garantidas, gênero e raça não especificarão pontos de vista relevantes" (RAWLS \& KELLY, 2001, p. 66) ${ }^{15}$.

Logo depois emenda que questões "sérias" relacionadas a gênero e raça não estavam na agenda de $A$ Theory of Justice, que se concentrou em problemas clássicos da teoria da justiça no âmbito da teoria ideal. Diz também que o livro foi omisso em relação a tais questões, para concluir que: "Justiça como equidade, e outras concepções como ela, certamente seria seriamente defeituosa se não tivesse recursos para articular valores políticos essenciais para a justificação das instituições legais e sociais necessárias para garantir a igualdade de mulheres e minorias" (ibidem) ${ }^{16}$.

Algumas conclusões importantes podem ser tiradas da análise acima. A compatibilidade entre a teoria de

\footnotetext{
15 Tradução nossa da passagem: "When used in a certain way, distinctions of gender and race give rise to further relevant positions to which a special form of the difference principle applies (Theory, §16: 85). We hope that in a well-ordered society under favorable conditions, with the equal basic liberties and fair equality of opportunity secured, gender and race would not specify relevant points of view" (idem, p. 66).

16 Tradução nossa da passagem: "Justice as fairness, and other liberal conceptions like it, would certainly be seriously defective should they lack the resources to articulate the political values essential to justify the legal and social institutions needed to secure the equality of women and minorities" (ibidem).
}

Rawls e o princípio da ação afirmativa em geral foi rápida e facilmente comprovada, enquanto que a potencial justificação de políticas de corte étnico-racial por tal teoria é mais complicada e depende de interpretação. Nos trechos em que fala sobre o assunto, ainda que de maneira indireta, o autor apresenta uma argumentação um pouco convoluta, expressando opiniões que não permitem uma interpretação unívoca. De um lado, fica claro que Rawls não vê necessidade de considerar tais categorias no plano da teoria ideal. Ao mesmo tempo, dá vários indícios de que tais posições têm de ser levadas em conta em sociedades onde elas são determinantes na produção de desigualdades injustificáveis.

Em algumas passagens, Rawls sugere que a variável renda dá conta de todas as posições relevantes pelas instituições em uma sociedade bem-ordenada, mas novamente acrescenta que se as posições de gênero e raça são relevantes, então elas devem merecer a aplicação dos princípios da justiça. A última passagem, citada acima, aponta para uma possível solução: tanto a justiça como equidade, como outras concepções liberais de justiça, devem promover valores que justifiquem instituições que garantam a igualdade das mulheres e outras minorias. Isto é, no final das contas, a interpretação mais razoável é de que ações afirmativas de gênero e étnico-raciais são sim justificáveis desde que tenham como horizonte normativo a igualdade.

É preciso ficar claro que não se trata aqui da afirmação da diferença cultural pura e simplesmente, como asseveram defensores do princípio da diversidade e/ou do relativismo cultural. Nem se trata, tampouco, de um argumento de reparação, lastreado na história de opressão das mulheres ou de minorias étnicas, mas sim da efetiva desigualdade de oportunidades e bens primários aos quais são submetidos em uma determinada sociedade.

Em suma, Rawls não trata diretamente do assunto das ações afirmativa étnico-raciais, quando muito se aproxima de modo oblíquo dele e, quando o faz, seus argumentos carecem de clareza. Ainda assim, o sentido geral, se podemos arriscar uma interpretação da teoria de Rawls, e achamos que podemos, é que em sociedades onde a posição étnico-racial marca desigualdades significativas, políticas que visam a promoção da igualdade, ou seja, que combatam tal efeito nocivo, são justificáveis.

\section{OUTRAS VISÕES DO LIBERALISMO-IGUALI- TÁRIO EAAÇÃO AFIRMATIVA}

Em curto artigo comentando exatamente a relação entre a teoria de Rawls e a ação afirmativa (racial), escrito logo após a morte do filósofo, Thomas Nagel, 
adepto do liberalismo igualitário que teve Rawls como orientador de sua tese de doutorado, confirma nossa leitura acerca da falta de uma abordagem direta a esse tema nos escritos do autor. O fulcro do argumento de Nagel é que Rawls dedicou-se a filosofar sobre teoria ideal, isto é, sobre como seria a sociedade justa, mas ela não diz, caso se esteja vivendo em uma sociedade injusta, o que fazer para corrigir essa injustiça (NAGEL, 2003 , p. 82). Na verdade, como lembra corretamente Nagel, Rawls tratou somente de duas questões pertinentes à teoria não-ideal: a desobediência civil e a objeção consciente à guerra injusta. No tocante a esses tópicos, Nagel não faz mais do que afirmar o que o próprio Rawls havia dito ao refletir sobre seus escritos anteriores em Justice as Fairness.

Nagel atribui a falta do tema ao fato de $A$ Theory of Justice ter sido publicada no começo da década de 1970 e, assim, refletir o estado de espírito da época, fortemente marcado pelos acontecimentos do decênio anterior. Daí a questão da desobediência civil e da recusa a participar na guerra. Por ter sido criada somente em meados da década de 1960 e virado assunto quente no debate público após a publicação de $A$ Theory of Justice, particularmente com o caso Bakke, de 1978, o autor não teria dado tanta importância ao tópico. Tal justificativa é deveras frágil, pois, como mostramos, Rawls teve a oportunidade de publicar uma edição revista de $A$ Theory of Justice, além de outros dois livros onde rearticula sua teoria, e isso em um ambiente em que não só a ação afirmativa para negros já havia se tornado uma questão relevante no debate público dos Estados Unidos, mas também os tópicos mais amplos do multiculturalismo e dos direitos de minorias, umbilicalmente ligados ao tema da ação afirmativa. Inclusive no âmbito da teoria política alguns dos autores que trouxeram essas questões à baila, como os comunitaristas Michael Sandel (1982) e Michael Walzer (1983), foram também críticos acerbos da teoria da justiça como equidade de Rawls. De fato, a "desculpa” dada por Nagel é pouco convincente. Poderíamos conjecturar o porquê de Rawls ter sido tão vago e omisso, mas mais importante que tais conjecturas é a constatação de que ele de fato raramente discutiu a aplicação de sua teoria ao plano menos abstrato das políticas públicas. Essas são citadas sempre como exemplos de passagem em seu texto. A ação afirmativa não é exceção.

Já Nagel não se furta a discutir a teoria não-ideal. Para ele, a sociedade americana é inegavelmente marcada pela discriminação racial, e tal discriminação produz um esquema extremamente injusto de distribuição de oportunidades. Assim, a ação afirmativa racial seria plenamente justificada como política que visa dirimir tal injustiça. Segundo o autor, uma sociedade justa não necessitaria de "preferências raciais", pois elas constituiriam em si um tipo de injustiça. Mas em uma sociedade injusta, marcada por séculos de discriminação e pelo crime da escravidão, essas “medidas excepcionais são necessárias se elas servem no longo prazo para retificar a situação não-ideal a qual tais injustiças nos levaram" (NAGEL, 2003, p. 84).

O texto ainda contém um dado muito interessante, ainda que de natureza biográfica e pessoal, mas que é em si revelador. Nagel diz lembrar de que, na época em que o caso Bakke estava sendo julgado, Rawls chamou atenção, em uma conversa particular, para importância de que a constitucionalidade da ação afirmativa fosse defendida. Um dado que diz muito acerca das preferências políticas do cidadão por trás do "autor" e, mais importante, insinua que a recusa em debater problemáticas concretas era uma opção deliberada, não somente um lapso ou desatenção.

Nagel trata do tema da ação afirmativa racial em outros textos mais elaborados. Sua posição geral não é muito diferente da de Rawls, mas é bem mais detalhada e contém elementos não considerados por seu orientador de doutorado. Ela pode ser resumida pela fórmula: a discriminação compensatória expressão sinônima de ação afirmativa - não é uma consequência necessária da justiça, mas é compatível com ela. Ademais, o autor assevera que tal política não é "seriamente" injusta, e que ela pode ser justificada não pela (teoria da) justiça em si, mas por considerações de utilidade social (NAGEL, 1973). A discussão do autor foca-se em grande parte na questão do mérito, ou seja, do reconhecimento da habilidade e dos talentos pelas instituições sociais que distribuem bens. Assim, a discriminação compensatória poderia ser considerada seriamente injusta se a distribuição de oportunidades e prêmios se desse exclusivamente segundo as variáveis da habilidade natural e inteligência - em si fatores que podem produzir desigualdades injustas, como assevera Rawls. Mas como o sistema de distribuição de oportunidades é fortemente distorcido por discriminação de gênero e de raça, a discriminação compensatória torna-se uma medida $(i)$ justificável do ponto de vista da utilidade social e (ii) que não produz sérias injustiças.

$\mathrm{O}$ apoio de Nagel às políticas de ação afirmativa não é sem ressalvas. Primeiro, ele diz que tais políticas só podem ser justas se compensarem pelas desvantagens específicas que são produto de injustiças (racismo e discriminação racial, por exemplo), mas logo depois afirma que é muito difícil estimar precisamente essas desvantagens e que elas variam de indivíduo para indivíduo. Em seguida, emenda que, mesmo quando tais justificativas existem, não é claro que elas causem obrigação, pois a noção de que um elemento da 
sociedade pluralística deva responsabilizar-se pela injustiça cometida por outro elemento ou mesmo pela sociedade como um todo é dúbia (idem, p. 358).

Em suma, se comparado à posição de Rawls, podemos dizer que ambos partilham um apoio reticente. Enquanto Rawls prefere abordar o tema lateralmente, sem "comprometer-se" com posições mais substanciadas, Nagel trata o assunto com mais detalhe e dá um apoio com ressalvas.

Talvez Ronald Dworkin seja o autor associado à corrente da justiça como equidade que mais escreveu sobre a ação afirmativa. Um ano antes da Suprema Corte deliberar sobre o já citado caso Regents of University of California v. Bakke, Dworkin publicou um capítulo inteiro de Taking Rights Seriously, onde examina a questão da constitucionalidade dessas medidas (DWORKIN, 1977, p. 223). Alguns anos mais tarde, ele voltaria ao tema em $A$ Matter of Principle (DWORKIN, 1985), reiterando sua defesa da ação afirmativa racial $^{17}$.

Em ambos os textos, Dworkin investe contra a crítica de que a ação afirmativa para os negros no ensino superior visa produzir uma sociedade "balcanizada", dividida em diferentes raças ou culturas. Para ele, a sociedade americana já seria fortemente "racializada" (racial conscious) e isso seria uma "consequência inevitável e evidente de uma história de escravidão, repressão e preconceito" (idem, p. 294). Nesse cenário, a ausência de profissionais especializados negros seria não só um resultado dessa situação, mas, sobretudo, uma causa potencial para a reprodução da segregação e do preconceito.

Dworkin contempla o argumento de que as ações afirmativas raciais poderiam ter o efeito reverso e levar justamente à autovitimização dos beneficiários, bem como a uma estigmatização perante a sociedade como

17 O caso Bakke, como ficou conhecido, originou-se da ação movida por Allan Bakke, um homem branco de 32 anos, contra a Universidade da Califórnia, pedindo para ser admitido pela Escola de Medicina da referida universidade. Para tal, Bakke argumentava que o programa de ação afirmativa praticado pela Escola, que o havia preterido, fosse declarado ilegal (SCHWARTZ, 1988; BALL, 2000). A decisão final da Corte, que ficou a cargo do juiz Powell, reza que, enquanto o uso de critérios étnico-raciais em programas de admissão é constitucional, a reserva de cotas não o é (MCPHERSON, 2005). Tal decisão não terminou com a controvérsia sobre o tema (ver, por exemplo, a interpretação de MacIntyre (1981)), mas estabeleceu um precedente de interpretação que foi utilizado em outros casos na Suprema Corte sobre o tema, como os casos mais recentes dos programas de ação afirmativa da Universidade de Michigan. Gratz v. Bollinger, Grutter v. Bollinger (STOHR, 2004; PERRY, 2007). um todo. Porém, ele considera que esses argumentos apoiam-se em predições incertas e contestáveis (DWORKIN, 1977, p. 224). Por isso, seu foco de análise recai sobre os contra-argumentos de natureza moral que até podem reconhecer a provável eficácia da diretriz, mas afirmam que ela baseia-se em distinções raciais injustas em si, na medida em que violam os direitos e méritos de indivíduos isolados (idem, p. 224). Nas palavras de Dworkin, “o argumento popular feito em editoriais é que Bakke tem o direito de ser julgado com base no seu mérito. Ou que ele tem o direito de ser julgado como um indivíduo mais do que como um membro de um grupo social. Ou que ele tem o direito, tal qual qualquer homem negro, de não ser sacrificado ou excluído de qualquer oportunidade por causa exclusivamente de sua raça. Mas essas frases de efeito [catch phrases] são enganosas aqui porque, como uma reflexão demonstra, o único princípio genuíno que elas descrevem é o princípio que ninguém deveria sofrer com o preconceito ou desprezo de outros. E esse princípio não está em jogo neste caso de forma alguma" (DWORKIN, 1985, p. 298).

Dworkin afirma que é preciso recusar um conceito essencialista e inato de inteligência, admitindo que todo mérito surge de uma adequação entre talentos adquiridos socialmente em uma estrutura social desigual e as necessidades contextuais de uma comunidade - uma concepção mais sofisticada que a de Rawls, que em $A$ Theory of Justice trata o talento natural como se fosse um dado que pudesse ser tomado independentemente dos processos de socialização e aprendizado. Segundo Dworkin, da mesma forma que uma grande habilidade faz com que um cirurgião tenha mais "mérito" que outro menos habilidoso, a cor da pele pode facilitar a comunicação e o trabalho como um todo de um médico que atende muitos negros e, portanto, dotá-lo de "mérito" também (idem, p. 299). Aqui o ponto de Dworkin não é naturalista ou de caráter biológico, isto é, ele não está afirmando que há uma especificidade da saúde das populações negras, mas sim que em uma sociedade segregada, com razoável grau de discriminação e preconceito, ser capaz de atender uma população marginalizada constitui em si um mérito. E essa capacidade tem a ver tanto com estar disposto a fazêlo quanto a ser bem aceito por aquela população.

Em segundo lugar, Dworkin adota os princípios rawlsianos que rezam que uma sociedade justa é aquela em que o Estado assume a tarefa de garantir que toda pessoa tenha a mais ampla liberdade, compatível com a mais ampla liberdade para os outros, e que desigualdades de poder, renda, bem-estar, oportunidades e outros recursos básicos não sejam 
legítimas, exceto se porventura beneficiarem os menos favorecidos, mantendo as posições sociais abertas a todos em condições de igualdade equitativa de oportunidades (DWORKIN, 1977, p. 150). Mas confere-lhes outra interpretação progressista e não utilitarista18: "não há[veria] nada paradoxal [...] na ideia de que um direito individual à igual proteção possa às vezes entrar em conflito, por outro lado, com uma política social desejável, incluindo a política que visa tornar a comunidade mais igualitária como um todo" (idem, p. 226). Isso porque não se pode confundir o direito fundamental de ser tratado como um igual e o direito condicional de receber igual tratamento. Se este último fosse um direito fundamental, então bastaria que um candidato obtivesse o direito de frequentar a universidade para que todos os demais reivindicassem um igual tratamento. Ser tratado como um igual, por seu turno, implica ter seus interesses considerados como os dos outros que se encontram na mesma condição (idem, p. 227).

Do momento que um processo seletivo estabelece o desempenho em testes como um critério de corte, um candidato que tirou uma nota baixa não pode reivindicar o direito a igual tratamento para exigir ser tratado da mesma forma que os candidatos que tiveram maior pontuação. Mas ele pode reivindicar o direito de ser tratado como um igual para receber um benefício caso outro candidato com uma nota igual tenha recebido o mesmo bônus. Portanto, a utilização de um critério racial funciona da mesma maneira que o critério que considera o desempenho ou inteligência (idem, p. 228). Dessa ótica, a ação afirmativa é vista como uma política em nada conflitante com as exigências básicas do liberalismo e, mais do que isso, como diligente na matização da desigualdade. Ela promoveria, portanto, a realização do princípio da diferença propalado pela justiça como equidade de Rawls.

Dworkin faz questão de marcar a diferença entre uma defesa idealista da ação afirmativa, que concebe a medida como um meio para a construção de um estado de coisas visto como ideal do ponto de vista da justiça como equidade, e uma defesa meramente utilitária. Nesta última, o prejuízo dos candidatos (brancos) preteridos se justificaria diante de um bem maior, a saber, o aumento do bem-estar médio da população de uma dada coletividade graças à introdução

18 Os caráteres progressista e anti-utilitário são elementos fundamentais do liberalismo igualitário e unem as teorias de Rawls e Dworkin. O argumento básico defendido pelos autores, por tantos outros liberais desde o século XIX, é o de que o utilitarismo é no fundo antiliberal, pois permite a violação dos direitos básicos do indivíduo em nome do aumento do bemestar da maioria. de contingentes (negros) excluídos da universidade (idem, p. 226). O problema do utilitarismo é que por trás do igualitarismo dessa justificativa está a ideia de que sempre é justo e adequado incrementar o bemestar médio dos indivíduos de uma dada coletividade, mesmo quando esse aumento dá-se às expensas de um indivíduo ou de um grupo deles. Assim, segundo Dworkin, esse argumento poderia ser utilizado para justificar políticas de segregação racial, por exemplo, caso um número razoável de pessoas considerasse fundamental para o seu bem-estar tal providência (idem, p. 234-238).

Note-se que Dworkin não distingue, como outros teóricos do liberalismo igualitário as ações afirmativas mais brandas das mais rígidas ou radicais. Nem mesmo procede como Nagel e Rawls, que parecem apoiar as ações afirmativas raciais, porém de forma vacilante. Para ele, a decisão do Ministro da Suprema Corte norte-americana Lewis Powell por ocasião do caso Bakke - que proibiu cotas raciais mas permitiu que a raça seja levada em conta como critério de admissão -, foi "uma recomendação de hipocrisia" (DWORKIN, 1985, p. 295). Segundo Dworkin, ao mesmo tempo em que essa decisão aceita que uma proporção mais equânime de negros no ensino superior seria uma meta justa, ela condena os procedimentos que adotam tal objetivo explicitamente. Para o autor, do ponto de vista da legalidade, a política de soft targets que passou a ser usada depois da decisão da Suprema Corte não é diferente da reserva por cotas, pois nos dois casos adotam-se critérios diferenciados para julgar os candidatos com vistas a favorecer os menos privilegiados. A única diferença é que no caso de $s o f t$ targets a proporção em que isso é feito não é clara, ao contrário das cotas.

Logo, é nesse último ponto que as conclusões de Dworkin polemizam com as de alguns de seus companheiros liberais igualitários. Segundo Robert Taylor, professor de Filosofia Política da Universidade da Califórnia, a teoria da justiça como equidade de Rawls não fornece bases para a defesa da ação afirmativa. Ou melhor, Taylor argumenta que a teoria rawlsiana não dá suporte moral à maioria das modalidades de ação afirmativa em voga quanto mais às modalidades mais extremas como as cotas raciais. Para o autor, as cotas raciais estabelecem que determinados resultados são mais justos que outros. Por estabelecer, ainda que implicitamente, uma meta, a cota racial seria uma medida eminentemente "teleológica" e, portanto, violaria o caráter radicalmente "procedimentalista" da teoria de Rawls (TAYLOR, 2009 , p. 502). Em outras palavras, a política, em vez de focar a igualdade de oportunidade defendida por Rawls, focaria a igualdade de resultados, o que violaria 
o espírito da teoria.

Grosso modo, de uma perspectiva teleológica, uma política pública justa é aquela capaz de gerar resultados sociais considerados úteis ou virtuosos de um dado ponto de vista. Já de uma perspectiva procedimentalista, uma política justa seria aquela que se baseia em procedimentos justos em si, independemente das concepções de bem dos indivíduos. Liberais procedimentalistas como Rawls não se cansam de afirmar que só procedimentos justos podem gerar resultados justos, e não o oposto. Como é notório, Rawls defende que sua teoria da justiça não assume a priori nenhuma concepção de bem determinada - esse ponto é claramente exposto já em A Theory of Justice, na passagem em que o autor critica o utilitarismo (RAWLS, 1971, p. 25). Contra as teleologias morais, ele apresenta uma visão procedimental de justiça cujo objetivo fundamental seria legitimar uma reorganização social que permitisse a cada indivíduo buscar sua respectiva concepção de bem. Para que esse ideal realize-se, várias restrições são impostas à ordem social de modo a coibir que alguns indivíduos utilizem outros para alcançarem fins vistos como bons em si mesmos (idem).

O ponto central do argumento de Robert Taylor é que nenhum resultado distributivo é justo per se. Somente quando o procedimento de partilha de um dado recurso for justo é que o resultado o será (TAYLOR, 2009, p. 492). Para Rawls, uma sociedade injusta não é simplesmente uma sociedade iníqua, mas sim aquela sociedade em que a desigualdade foi produzida por procedimentos desiguais na consideração dos indivíduos. Por isso, Taylor argumenta que as cotas raciais seriam contrárias a esse espírito procedimental da justiça como equidade na medida em que mudam os processos seletivos a partir de uma concepção de resultado justo.

Contra Taylor, pode-se objetar que qualquer intervenção redistributiva não seria totalmente procedimental, pois sempre se justificaria por uma presunção de que um resultado mais proporcional é melhor (TAYLOR, 2009, p. 497). Taylor rejeita essa crítica lembrando que o que caracteriza o procedimentalismo não é a ausência total de um desejo de proporcionalidade, mas sim a inconsciência e a ausência de controle sobre tal resultado (idem, p. 498). Como não é possível determinar ex ante quais desigualdades são justas ou injustas, a solução mais justa seria a adoção de procedimentos de redistribuição vistos como justos em si (ibidem).

Deve-se notar que Robert Nozick faz uma crítica muito similar à de Taylor, mas dirige-a não contra as políticas de ação afirmativa, mas à teoria de Rawls como um todo. Segundo Nozick, ao levar em consideração posições relevantes que representam categorias de indivíduos da sociedade real, posições essas mormente de renda e riqueza, os princípios da justiça de Rawls estariam olhando para o resultado final da distribuição e operando a redistribuição a partir dele (NOZICK, 1974, p. 208). Assim, a teoria proposta por Rawls não seria meramente procedimental, mas sim um conjunto de procedimentos determinados por resultados finais reiteradamente. Mas, ao compararmos as críticas de Taylor e de Nozick, chegamos a um paradoxo, pois se Nozick está correto, e a teoria da justiça de Rawls opera por meio de uma avaliação reiterada dos resultados, então, não há por que classificar a ação afirmativa como uma medida estranha à teoria - quase todas as políticas do Estado de BemEstar Social operam pela imposição de procedimentos a partir da interpretação reiterada de resultados. E, assim, Taylor estaria necessariamente incorreto ao isolar a ação afirmativa como uma política que viola os princípios teóricos de Rawls.

Por outro lado, se Taylor estiver correto ${ }^{19}$, a fama de teórico que sistematizou os fundamentos filosóficos e morais do Estado de Bem-Estar Social, angariada por Rawls, seria infundada, com o perdão do trocadilho: quase todos os comentadores, críticos ou apologistas, estariam enganados a respeito do significado da contribuição do professor de Harvard. Ademais, se sacarmos o elemento iterativo da teoria da justiça de Rawls, ou seja, o processo de retroalimentação no qual resultados finais são convertidos em situações iniciais para um novo ciclo de operação das instituições promotoras de justiça, o edifício todo desmorona, o que nos leva a concluir que o argumento de Taylor tem problemas graves para se sustentar.

Outra objeção possível seria a de que a quase completa ausência de negros em instituições de ensino superior já seria razão suficiente para justificar a adoção de cotas mínimas, o que poderia ser feito sem defender necessariamente uma concepção de bem clara (TAYLOR, 2009, p. 500). Em um contexto em que negros estão totalmente ausentes da universidade, estabelecer uma cota mínima de $10 \%$ das vagas para eles reduziria o grau de injustiça no curto prazo e, simultaneamente, não demandaria um conhecimento completo da proporção ideal. Porém, para Taylor, como

\footnotetext{
19 Devemos notar que sua crítica não se dirige à ação afirmativa étnico-racial, mas a todo tipo de ação afirmativa e, consequentemente, a todas as políticas públicas que procedam redistribuição a partir dos resultados dados em um determinado momento (aquilo que Nozick ironicamente chama de teorias time-slice) (NOZICK, 1974, p. 153).
} 
continuamos sem conhecer de antemão a proporção ideal, a tendência é reproduzir indefinidamente a injustiça nos $10 \%$ fixados. Por isso, Taylor só admite modalidades extremamente brandas de ação afirmativa. Segundo o autor, uma ação afirmativa só seria justa quando $(i)$ houvesse um conhecimento extremamente confiável da distribuição igualitária ideal de um dado recurso, (ii) a situação em que ela fosse aplicada estivesse muito distante de um ideal minimante justo, (iii) outras políticas tivessem comprovado sua ineficácia $(i v)$ e nas quais se estabelece uma cota mínima, temporária e emergencial como um "primeiro empurrão" (idem, p. 501-502).

\section{CONCLUSÕES}

O estudo da argumentação pública requer um esforço de examinar os vários regimes discursivos que justificam decisões relevantes em nossa sociedade. Esse esforço é necessariamente multidisciplinar, pois justificações públicas, sejam elas feitas em debates na mídia, em votos de ministros do Supremo ou em discursos parlamentares, fazem uso de um repertório amplo e variado, onde se combinam conhecimentos técnicos e populares, Ciências Sociais, teoria moral e teoria política. No caso do debate sobre a constitucionalidade das políticas de ação afirmativa, que recentemente teve grande destaque devido à decisão do Supremo Tribunal Federal, o recurso à teoria moral e política é frequente, em parte porque tal teoria fornece subsídios para o próprio direito constitucional. Assim, a presente contribuição pretende usar do formato do artigo científico, com seu espaço de reflexão raramente encontrado em outros meios de divulgação comunicativa, para lançar luz a uma questão de imediata relevância em nossa sociedade. Quais a conclusões retiradas de nosso exercício?

A primeira e talvez mais relevante é a de que a associação entre liberalismo igualitário e políticas de ação afirmativa de corte étnico-racial, ainda que seja feita de maneira reiterada nos discursos da mídia e do próprio poder Judiciário, não é automática e sem tensões. Mostramos que o principal autor desse enfoque, John Rawls, foi reticente ao abordar o tema, ainda que possamos sacar do todo de sua obra, a guisa de interpretação indireta, uma posição favorável. Rawls preferiu evitar o tema usando o argumento de que ele não pertence à teoria ideal, mas ao caso de sociedades profundamente desiguais, que devem ser tratadas no plano da teoria não ideal. Nagel, seu pupilo, baixa ao plano da teoria não ideal. Sua conclusão é favorável, mas não sem ressalvas. A ação afirmativa racial não seria injusta, mas tampouco estritamente uma consequência necessária da aplicação dos princípios da justiça.
Ronald Dworkin é o autor identificado com o liberalismo igualitário que mais decididamente defende políticas de ação afirmativa étnico-raciais. Mas temos de levar em conta o fato de que os argumentos apresentados por ele são de ordem teleológica e comunitária e em grande parte condicionados a interpretações pertinentes à sociedade norte-americana, isto é, não são propriamente decorrentes dos princípios de sua teoria da justiça. Já Robert Taylor é o mais contrário, enxergando uma contradição entre essas políticas, vistas como voltadas a corrigir resultados, e o procedimentalismo fundamental da proposta rawlsiana. Taylor, em certo sentido, faz movimento contrário ao de Nagel, pois da declaração da inadequação das políticas caminha para sua aprovação condicionada a critérios estritos de necessidade. Eles partem de lugares opostos para chegaram a conclusões práticas muito similares.

Se assumirmos uma perspectiva histórica, é impossível negar que as políticas de ação afirmativa de corte étnico-racial surgiram em sociedades cujo regime político-moral - inclusive plasmado nas instituições, entre elas a própria constituição - é a democracia liberal: Índia, Estados Unidos, Brasil etc. A despeito de ser uma teoria em constante mutação desde seus primórdios, o liberalismo tem um acento marcadamente racionalista, abstrato, individualista e universalista. No âmbito do direito constitucional brasileiro, esse acento talvez seja ainda mais forte devido a grande influência do positivismo jurídico, que tem como figura de destaque Hans Kelsen, que por seu turno era kantiano. Assim, é natural que uma política que confira direitos e privilégios a um grupo específico de pessoas tencione os pressupostos universalistas e formalmente abstratos da fundamentação liberal.

Ainda de uma perspectiva histórica, é fato que desde pelo menos a década de 1930 as sociedades de recorte democrático-liberal procuram soluções para as mazelas geradas pelo exercício continuado de instituições baseadas em critérios universalistas e formalmente abstratos, entre elas figura com destaque a desigualdade extremada. O liberalismo igualitário, como o próprio nome sugere, é um esforço para dar solução teórica a essa tensão, solução essa que preserve as bases do liberalismo ao mesmo que justifique a operação de mecanismos promotores de maior igualdade. Também é inegável que as políticas de ação afirmativa, inclusive as de recorte étnico-racial, foram criadas no bojo de um movimento de expansão progressista do Estado de Bem-Estar Social, e, como tal, partilham com várias outras políticas desse regime o mesmo princípio de funcionamento, a discriminação positiva. Consequentemente a despeito da variedade 
das posições teóricas do liberalismo igualitário em relação à ação afirmativa, ambos habitam o mesmo lugar no espectro ideológico da democracia liberal: a esquerda progressista, ou reformista, se quisermos resgatar um vocabulário cujo uso é cada vez menos corrente.

Neste ensaio, pretendemos ter proporcionado uma avaliação detalhada da possibilidade de justificação das políticas de ação afirmativa de corte étnico-racial com bases no liberalismo igualitário, levando em conta vários de seus principais autores. Tal abordagem à teoria moral e política não é a única a produzir justificativas públicas nas sociedades democrático-liberais. Como dissemos na introdução, o comunitarismo, o multiculturalismo e a teoria do reconhecimento também podem ser usados na justificação pública da ação afirmativa. Infelizmente, devido ao espaço limitado do formato artigo de periódico, teremos que deixar o exame dessas outras abordagens para uma oportunidade futura.

João Feres Júnior (jferes@iesp.uerj.br) é Doutor em Ciência Política pela City University of New York (CUNY) e Professor no Instituto de Estudos Sociais e Políticos da Universidade Estadual do Rio de Janeiro (IESPUERJ).

Luiz Augusto Campos (luiz.campos@unirio.br) é Doutor em Sociologia pelo Instituto de Estudos Sociais e Políticos da Universidade Estadual do Rio de Janeiro (IESP-UERJ) e Professor da Escola de Ciência Política da Universidade Federal do Estado do Rio de Janeiro (UNIRIO).

\section{REFERÊNCIAS BIBLIOGRÁFICAS}

BALL, H. 2000. The Bakke Case: Race, education, and affirmative action, Landmark law cases \& American society. Lawrence: University of Kansas.

DAHL, R. A. \& FLANIGAN, W. H. 1971. The New Haven Community Study: Yale University, Summer 1959. Rev. ICPR ed. Ann Arbor: Inter-University Consortium for Political Research.

DWORKIN, R. 1977. Taking Rights Seriously. Cambridge (MA): Harvard University.

. 1985. A Matter of Principle. Cambridge (MA): Harvard University.

FERES JÚNIOR, J. 2004. Ação Afirmativa no Brasil: fundamentos e críticas. Econômica, Rio de Janeiro, v. 6, n. 2, p. 291-312, dez. Disponível em: http:// www.proppi.uff.br/revistaeconomica/sites/default/ files/V.6_N.2_Joao_Feres_Junior.pdf. Acesso em: 17.set.2013.

GOMES, J. B. B. 2001. Ação afirmativa e princípio constitucional da igualdade. Rio de Janeiro: Renovar.

HAYEK, F. A. V. 1960. The Constitution of Liberty. Chicago: University of Chicago.

KAMEL, A. 2003. Não somos racistas. O Globo, Rio de Janeiro, 9.dez.

KYMLICKA, W. 1995. Multicultural Citizenship: A liberal theory of minority rights (Oxford political theory). Oxford: Oxford University.

2001. Politics in the Vernacular: Nationalism, multiculturalism, and citizenship. Oxford: Oxford University.

LEWANDOWSKI, R. 2012. Argüição de descumprimento de preceito fundamental 186. Brasília: Superior Tribunal Federal. Disponível em: http://www.stf.jus.br/arquivo/cms/ noticiaNoticiaStf/anexo/ADPF186RL.pdf. Acesso em: 17.set.2013

MACINTYRE, A. C. 1981. After Virtue: A study in moral theory. Notre Dame: University of Notre Dame.

MCPHERSON, S. S. 2005. The Bakke Case and the Affirmative Action Debate: Debating Supreme Court decisions, Debating Supreme Court decisions. Berkeley Heights: Enslow.

NAGEL, T. 1973. Equal Treatment and Compensatory Discrimination. Philosophy and Public Affairs, Princeton, v. 2, n. 4, p. 348-363, Summer.

.2003. John Rawls and Affirmative Action. The Journal of Blacks in Higher Education, New York, n. 39, p. 82-84, Spring.

NOZICK, R. 1974. Anarchy, State, and Utopia. New York: Basic.

PERRY, B. A. 2007. The Michigan Affirmative Action Cases, Landmark Law Cases \& American Society. Lawrence: University of Kansas.

RAWLS, J. 1971. A Theory of Justice. Cambridge (MA): Harvard University. 
1993. Political Liberalism: John Dewey essays in Philosophy. New York: Columbia University.

1999. A Theory of Justice. Rev. ed. Cambridge (MA): Harvard Univeristy.

RAWLS, J.\& KELLY, E. 2001. Justice as Fairness: A restatement. Cambridge (MA): Harvard University.

SANDEL, M. J. 1982. Liberalism and the Limits of Justice. Cambridge (UK): Cambridge University.

SANSONE, L. 2003. Blackness Without Ethnicity: Constructing race in Brazil. New York: Palgrave Macmillan.

SCHWARTZ, B. 1988. Behind Bakke: Affirmative action and the Supreme Court. New York: New York University.

STOHR, G. 2004. A Black and White Case: How affirmative action survived its greatest legal challenge. Princeton: Bloomberg.
TAYLOR, C. 1992. The Politics of Recognition. In: TAYLOR, C. \& GUTMANN, A. (eds.). Multiculturalism: Examining the Politics of Recognition. Princeton: Princeton University.

TAYLOR, R. 2009. Rawlsian Affirmative Action. Ethics, Chicago, n. 119, p. 476-506.

WALZER, M. 1983. Spheres of Justice: A defense of pluralism and equality. New York: Basic.

WEISSKOPF, T. E. 2004. Affirmative Action in the United States and India: A comparative perspective. New York: Routledge.

YOUNG, I. M. 1990. Justice and the Politics of Difference. Princeton: Princeton University.

ZONINSEIN, J. 2004. Minoriais étnicas e a economia política do desenvolvimento. Econômica, Rio de Janeiro, v. 6, n. 1, p. 105-121. jun. Disponível em: http://www.uff.br/revistaeconomica/v6n1/ sergei.pdf. Acesso em: 17.set.2013. 
EGALITARIAN LIBERALISM AND AFFIRMATIVE ACTION: FROM MORAL THEORY TO PUBLIC POLICY.

\section{João Feres Júnior e Luiz Augusto Campos}

This article examines the hipotheses that the political and moral theory of egalitarian liberalism provides a sound justification for ethnic and race-based affirmative action, something that has been deemed true by academics and Supreme Coutr justices in Brazil. We proceed by analysing how key authors associated with egalitarian liberalism, such as John Rawls, Ronald Dworkin, Thomas Nagel e Robert Taylor, approached the subject. The method used for such analysis was textual interpretation, which was conducted as close as possible to each author's language and concepts. Our endeavor covered the evolution of the theme in the works of each one, with a special focus to Rawls's contribution. Instead of a single connection, we found that there is a gradation of opinions regarding the topic, which stretches from the explicit justification of these policies to their entire rejection on moral grounds. Therefore, our results show that there inequivocal link between the moral and political theory of egalitarian liberalism and the justification of ethnic and racebased affirmative action, despite common-sense and the fact that liberal egalitarians and the advocates of affirmative action often share the same location on the political spectrum in liberal democractic societies.

KEYWORDS: political theory; affirmative action; egalitarian liberalism; justice; Rawls. 